\title{
Public Infrastructure Maintenance Practices in Ghana
}

\section{Edmund Nana Kwame Nkrumah ${ }^{1 *}$, Tindi Stephen ${ }^{2}$, Lydia Takyi' and Oswin Aganda Anaba ${ }^{1 *}$}

${ }^{1}$ School of Management, Jiangsu University, PRC

${ }^{2}$ Ghana Institute of Journalism

\begin{abstract}
This study assessed the maintenance practices and quality improvements of public infrastructure by adopting the National Theatre of Ghana as a case study. This research specifically examined maintenance practices of the National Theatre, a national asset and the biggest auditorium used by the country to host major national events. A single case study design was employed for the study. Both questionnaires and interviews were used to obtain data from sampled staff and management of the National Theatre. The study revealed that the maintenance practices at the theatre are mostly routine involving cleaning, fumigation and servicing. There are also quarterly and annual maintenance schedules, but all these are predictive and preventive maintenance works. The maintenance works at the theatre have also ensured that the National Theatre is serene and habitable in the short term. The maintenance practices also help to maintain the aesthetics and attraction of the theatre in the medium term, and in the long term, maintenance practices can forestall the sudden breakdown of major equipment hence prevented the sudden collapse of the entire facility. However, the study found a gap between maintenance practices and quality maintenance practices at the National Theatre. The theatre has not integrated quality management practices, hence some of the important long-term benefits of maintenance practices have been missed and there is a backlog of maintenance that need to be worked out. Staff of the National theatre are not oblivious to the backlog of maintenance that the facility faced with but suggested that this is a result of inadequate budgetary allocation for maintenance. The study concludes that increasing budgetary appropriation for maintenance, there is a need to improve public cooperation and support for the National Theatre in order to improve the quality of the edifice.
\end{abstract}

Keywords: Public; Infrastructure; Management; Practices

\section{Background of the Study}

The purpose of public infrastructure such as buildings and other facilities is to satisfy social and administrative needs as a means to the fulfilment of economic responsibilities for the general public [1]. In spite of this, the proper maintenance of public property has not been given the deserved attention. As a result, Ghana's development is restricted by a gaping infrastructural deficit and apparently poor maintenance of existing public property.

Efobi [2] and Anierobi observed that inadequate infrastructure and the poor maintenance of existing ones are typical characteristics of developing nations. Meanwhile, public infrastructure is essential for sustainable development of a nation hence improving the quality of state property is an important national decision. Efobi [2] and Anierobi explained that although developing countries continue to invest heavily in new infrastructure, the sustainably of existing ones suffer from poor maintenance culture. Maintenance is proactive. It includes activities that were undertaken in order to keep, restore and improve existing infrastructures to be appreciable standards and to sustain utility and value of the facilities over time.

Maintenance is an important aspect of projecting quality management. With regard to facility management in particular, Khan [3] regarded this as flexibility management and explained that construction projects require flexible management as these projects are unpredictable and managers need to cope with changes and challenges that sometimes are unexpectedly. Sequel to this, continuous maintenance activities are necessary to maintain or improve project quality. This means that proper maintenance is a good project management practice that contributes to project quality.

Historically, in the underfunded public sector, maintenance practices are poor because maintenance was perceived as an avoidable task and an insignificant addition to the quality of public property. Also, there was a concern for the expending of scarce resources that could be better placed. Owing to this, maintenance of public properties such as historical buildings, state offices, basic amenities and other publicly managed assets is awful in Ghana. This has driven some state properties to a point of virtual collapse while others continue to deface and lose value as a result.

The desire for improved maintenance practices is often expressed by activists, political leaders and the populace, but the appetite to execute is very low. Stemming from this, the issue of poor maintenance practices in Ghana has enjoyed public debate but without the necessary accompanying action. In as much as several studies in the field of safety science have addressed good infrastructure maintenance practices as a major issue in Ghana and African at large, there is no considerable amount of research addressing the issue of public infrastructure management. This study investigates the maintenance practices of public property with the goal to exploring "how maintenance practices and quality of public property can be improved in Ghana".

This investigation is empirically narrowed to the national theatre of Ghana, a national edifice of about twenty-four (24) years, was built and donated to the government of Ghana by the Chinese government. The theatre is a partially commercial national asset and multifunctional institution tasked with responsibility to develop and promote performing Arts. Over two decades of its existence, the facility has seen some minor maintenance works such as vacuuming, overhauling, painting and other face-lifting ground works, but its state still leaves more to be desired. Just like the National theatre, many historical

*Corresponding author: Edmund Nana Kwame Nkrumah, School of Management, Jiangsu University, PRC, Tel: +8618651400940; E-mail: Nkrunak@gmail.com

Received November 25, 2017; Accepted December 22, 2017; Published December 29, 2017

Citation: Nkrumah ENK (2017) Public Infrastructure Maintenance Practices in Ghana. Review Pub Administration Manag 5: 234. doi:10.4172/2315-7844.1000234

Copyright: @ 2017 Nkrumah ENK. This is an open-access article distributed under the terms of the Creative Commons Attribution License, which permits unrestricted use, distribution, and reproduction in any medium, provided the original author and source are credited. 
buildings, state infrastructure and other public assets do not benefit from any coordinated periodic maintenance. National monuments have defaced and deteriorated as a result of this dearth of quality management for publicly managed facilities.

The Herald newspaper reported that there are leakages in parts of the theatre ceiling, some air conditioners have broken down and parts of the floor in the main hall are also exposed from worn out carpets. At the exterior, the magnificent water fountain gracing the theatre's frontage has turned green with spirogyra and very smelly from months of water stagnation (The Herald). This condition has led to revenue losses to the theatre because event managers no longer consider the theatre for major events. The state of the theatre has also affected the frequency of tourist visits.

Following from the less desirable state of the National Theatre and the need to ensure proper maintenance of public property, this study investigates maintenance practices at the national theatre and focused on exploring how to improve upon the maintenance culture and quality management of the theatre by identifying the maintenance practices.

The study also examined the outcomes of the current maintenance practices by categorizing the practices into three major terms, thus:

a. In the short term

b. In the medium term

c. In the long term

Finally, the study assessed the views of senior and junior staff about the current maintenance practices and how well it can be improved.

The outcome of the study would enlighten the government, policy makers, property managers and other major stakeholders about the need improve the maintenance practices and quality of public properties. In addition, the retrospective nature of the study and the detailed exploration will serve as an evaluation of the institutionalized management practices at the national theatre for the purpose of improving the maintenance standards

\section{Literature Review: Theoretical Framework}

The state of public infrastructure in Ghana is appalling as maintenance of existing infrastructure is also generally poor. Maintenance practices are required to ensure that infrastructure and other valuable assets remain functional and productive. Campbell [4] made a business case for maintenance indicating that maintenance is one of nine other activities that should be considered in the asset management process. In the asset lifecycle model, Campbell [4] suggested that maintenance should be part of an overarching business strategy with definite indicators.

Campbell [4] opined that essential maintenance management has to do with activities such as planning, organizing, controlling and taking stock of accomplishments. The specific steps that make up the asset management cycle are the following nine steps: Asset strategy, plan, evaluate, design, create or procure, operate, maintain, modify and dispose. However, in one of the very extensive commentaries on the model, Mohamed [5] observed that the nine steps can be reduced to eight by taking out the last step. His position was that some assets by nature are not designed to be disposed after use.

The relationship between the eight-step asset management processes is illustrated in Figure 1.

\section{Adapted from Campbell, (1995)}

It can be observed from Figure 1 above that asset management

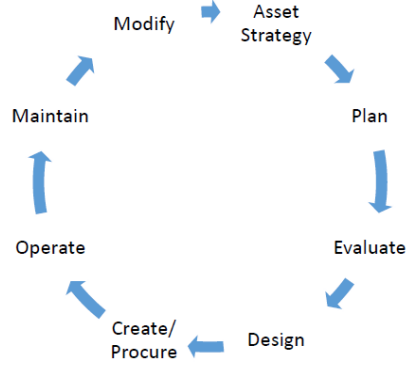

Figure 1: Asset management cycle.

according to Campbell [4] is strategic and begins with asking why the asset is required and how it relates to the business plan. The plan for the business is then subject to evaluation before the design of the asset needed to fulfil the purpose or business needed to be identified. The evaluation process ensures that the purpose, function and standards of performance are justified. The evaluation phase is very rigorous as this may also entail comparing cost to benefits and ranking of options. The evaluation process ends with approval which then kicks into motion design of the asset. After detailed design and specifications are completed, the asset is constructed or produced, and maintained or modified as time goes on. The focus of this study is the maintenance, operation, and modification processes but these processes are more effectively examined as parts of the continuum of activities in the asset management life cycle.

Molentze observed that although the asset management life cycle is aholistic view to maintenance management and improvement, these steps can also be narrowed into four relevant thematic considerations for asset management. The thematic categories represent major phases in the asset management life cycle. The four areas are acquisition, operation, maintenance and disposal phases.

One significant reason for maintenance is to ensure optimum or at least standardized performance. Sequel to this, Campbell [4] put forward three taxonomies of performance measure. These are taxonomies of performance measures are based on focal areas of asset performance. The three areas of focus are measures of equipment/ facility performance, measures of cost performance and measures of process performance. These measures are endorsed by Muchiri, Pintelon, Gelders and Martin [6] who described the three taxonomies as widely popular in maintenance literature.

However, Muchiri et al [6] argued that efficient performance management indicators should necessarily encapsulate issues of controlling and monitoring of performance and as well support maintenance actions towards achievement of asset management objectives. Muchiri et al. [6] suggested that some indicators are more comprehensive for measuring performance improvement. The indicators suggestions can be generally considered as process indicators and performance indicators. This model is presented in Figure 2.

\section{Adopted from Muchiri et al. (2010)}

It would be observed from the performance measurement framework that the maintenance strategy provides the background for leading performance indicators and lagging performance indicators. However, both the maintenance process (leading) indicators and maintenance results (lagging) indicators are vital for measuring the performance of the maintenance function [6]. For each essential element, the main encounter is to recognize the performance indicators that will express whether the essentials are managed well. 


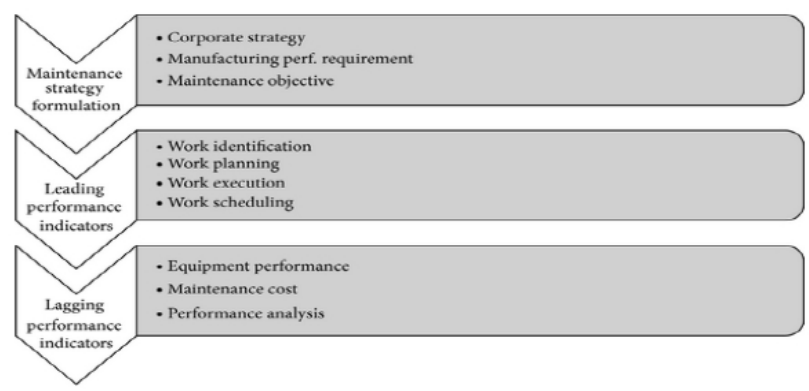

Figure 2: The performance measurement framework for maintenance function

\begin{tabular}{|c|c|}
\hline Quality element & $\begin{array}{c}\text { Description } \\
\text { Quality planning }\end{array}$ \\
$\begin{array}{c}\text { Focused on setting quality objectives and specifying } \\
\text { necessary operational processes and related resources to } \\
\text { fulfil the quality objectives }\end{array}$ \\
\hline $\begin{array}{c}\text { Quality control } \\
\text { Quality assurance } \\
\text { Qualing quality requirements } \\
\text { improvement }\end{array}$ & $\begin{array}{c}\text { Providing confidence that quality requirements will be fulfilled } \\
\text { Increasing the ability to fulfil the quality requirements }\end{array}$ \\
\hline \multicolumn{2}{|c|}{ Table 1: Elements of quality management. }
\end{tabular}

Thus, maintenance practices are expected to be inherently beneficial on two levels; leading indicators which refer work processes and lagging indicators which measure the outcomes of the entire maintenance process in terms of technical and economic benefits. Obviously, the leading indicators are more immediate, but the lagging indicators would take time to manifest as these are longer term. Sufficient to say, the leading indicators are beneficial for explaining the shortterm outcomes of maintenance practices whilst the lagging indicators are suitable for explaining the medium to long term outcomes of maintenance practices.

The maintenance measurement framework is adopted in this study to illustrate the observable short term, medium term and long-term effects of maintenance practices at the Ghana National Theatre.

\section{Quality management}

Mohamed [5] admonished that maintenance and quality management should not be decoupled but should be integrated as part of the corporate strategy to ensure continuous availability of equipment, production quality and competitive delivery.

Kaufmann and Wiltschko [7] noted that quality management is procedural and structured. It is defined by the International Standardization Organization ISO 9000 series as coordinated activities to direct and control an organization with regard to quality. Direction and control with regard to quality generally includes establishment of the quality policy and quality objectives, quality planning, quality control, quality assurance and quality improvement.

The various elements in the quality management continuum are briefly illustrated in Table 1.

\section{Adapted from (Wiltschko and Kaufmann, 2006)}

Quality management is also a very important concept in the project management. In the project management, it is simply a referent to all procedures and activities necessary to determine and attain project outcome. In principle, quality management in project is necessary to ensure customer satisfaction, continuous improvement and prevention of breakdown. Quality management as a project management concept has cost implications for the project. The cost of conforming to quality management practices (prevention costs and appraisal cost) are less than the costs of non-conformance (internal failure cost and external failure costs). Projects that do not conform to quality standards may lead to liability suites, warranty work, and even loss of business, these can be prevented through simple quality management practices [8].

Further, quality management is also a management philosophy, this is called Total Quality Management. This philosophy is described by the International Standardization Organization 9000 [9] as a management approach of an organization, centered on quality, based on the participation of all its members and aimed at long-term success through customer satisfaction, and benefited to the members of the organization and to the society.

The literature reviewed in this section shows that both quality management and maintenance are means to a common end of improved quality and productivity. It is however revealing to learn that quality management is part of the overall organizational strategy and must be reflected in all levels of the organization. This implies that structures, projects or equipment designed without inherent opportunities for continuous improvement may not stand the test of quality overtime.

\section{Research Methodology}

This study is an exploration into the maintenance culture of public buildings with a focus on the National Theatre of Ghana. The Mixed Research Method approach was employed for the study. This method involves combining well established qualitative and quantitative techniques to answer research questions posed. The mixed research method was suitable for this study because it ensured a balance such that the strengths of one research method mitigated the weaknesses of the other. As well the mixed method was adopted because of the explorative nature of this study.

Questionnaires and interview guides aiming to answer the research questions were employed to gather data from respondents. Respondents for this study were sampled from staff and occupants of Ghana National theatre. Some management members of the national theatre were also selected for interviews.

The target population for this study involves all occupants of the National Theatre and the managers of the facility. The National theatre is occupied by three resident companies; the National Dance Company, the National Symphony Orchestra, and the National Theatre Players.

The researcher employed both the probability and non-probability sampling techniques in selecting respondents to participate in the study. The stratified sampling technique was used in selecting fifty (50) respondents from staff of the various organizations that work from the National theatre building. Convenient sampling strategy was also used to select two (2) executives responsible for maintenance works and the management of the facility.

Stratified sampling entails the division of a study population into groups (strata). Each stratum is therefore treated separately, and a number of respondents are drawn from each stratum [10]. This approach was suitable for the study because it helped to gain sampling precision. Purposive sampling was also used to select two management members of the national theatre to participate in the study. The purposive sampling technique was used to identify two management members specifically for interview. Purposive sampling involves selecting respondents based on predetermined criteria that make them more suitable than other constituents of the population [11]. 
The analysis of data for this study was based on two levels because the study is a mixed study. Quantitative data collected through the use of questionnaires was analyzed descriptively via a computer softwareStatistical Package for Social Scientists (SPSS). Qualitative data obtained through interviews was also recorded, transcribed and subjected to thematic analysis. The thematic analysis related to close reading of interview responses in order to identify patterns. The patterns were later collapsed into themes for analysis.

\section{Discussion of Findings and Data Analysis}

This chapter presents the findings of the study with respect to the field research.

\section{Organizations in the theatre}

The organizations or institutions in which the various respondents worked are presented in Table 2.

Majority (60\%) of respondents worked with the National Theatre. Ten (10) respondents (20\%) represented the National Dance Ensemble and another 10 (20\%) represented the National Symphony Orchestra. In relation to the length of studies, majority of the respondents have worked within the National Theatre facility between 5-15 years.

The result of this is presented in Figure 3.

It is observed from Figure 4 that there are several maintenance practices undertaken at the Theatre. The diagram shows that, cleaning appears to be the most preponderant as this was selected by $80 \%$ of respondents. Repair work is also a quite common maintenance practice

\begin{tabular}{|c|c|c|}
\hline Organization & Frequency & Percentage \\
\hline National theatre & 30 & 60 \\
\hline National dance ensemble & 10 & 20 \\
\hline National symphony orchestra & 10 & 20 \\
\hline Total & 50 & 100 \\
\hline
\end{tabular}

Source: Field Data, (2017)

Table 2: Organization/institution.

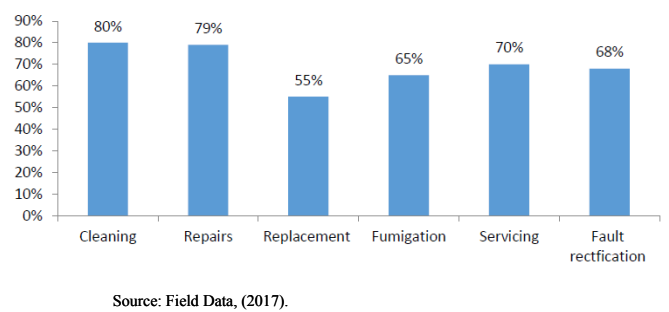

Figure 3: Maintenance practices of Ghana national theatre.

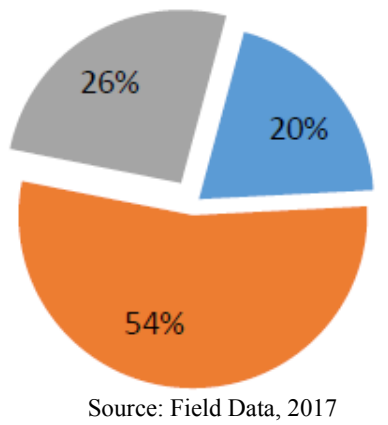

Major maintenance

Routine

Maintenance

Figure 4: Nature of maintenance practices at the national theatre.

\begin{tabular}{|c|c|c|c|c|c|}
\hline Maintenance Practice & SA & A & NA/DA & D & SD \\
\hline $\begin{array}{c}\text { Regular check up to } \\
\text { prevent breakdown }\end{array}$ & $50 \%$ & $30 \%$ & $20 \%$ & 0 & 0 \\
\hline $\begin{array}{c}\text { Predictive/condition based } \\
\text { maintenance }\end{array}$ & $20 \%$ & $20 \%$ & $24 \%$ & $36 \%$ & 0 \\
\hline $\begin{array}{c}\text { Corrective maintenance to } \\
\text { address existing problems }\end{array}$ & $75 \%$ & $25 \%$ & 0 & 0 & 0 \\
\hline $\begin{array}{c}\text { Emergency repair to quell } \\
\text { eminent danger }\end{array}$ & $22 \%$ & $68 \%$ & 0 & 10 & 0 \\
\hline $\begin{array}{c}\text { Breakdown maintenance } \\
\text { after equipment failure }\end{array}$ & $12 \%$ & $70 \%$ & 0 & $18 \%$ & 0 \\
\hline $\begin{array}{c}\text { On-going improvement } \\
\text { to avoid periodic } \\
\text { maintenance }\end{array}$ & $10 \%$ & $20 \%$ & 0 & $70 \%$ & 0 \\
\hline \begin{tabular}{c} 
Source: Field Data, 2017 \\
\hline
\end{tabular}
\end{tabular}

Table 3: Description of maintenance practices.

at the National Theatre as it was indicated by $79 \%$ of respondents. Other equally widely acknowledged maintenance practices undertaken at the National Theatre include servicing, fault rectification, fumigation and replacement.

Findings reveal that most of the maintenance works carried out at the National Theatre is routine maintenance. Majority (54\%) of respondents indicated that maintenance work at the theatre is routine in nature. However, 13 (26\%) of respondents consider maintenance works at the theatre to be periodic but $10(20 \%)$ of respondents indicated that the maintenance works at the theatre can be best described as major maintenance. The findings are illustrated in Figure 4.

In order to adequately understand the form and manner of maintenance practices undertaken at the National Theatre, respondents were further required to indicate the extent of their agreement or otherwise with various statements describing maintenance practices at the National Theatre. A five-point likert- type scale was employed to measure responses pertaining to the description of maintenance practices. The likert type scale was calibrated as follows: Strongly agree (SA), Agree (A), Neither Agree nor disagree (NA/DA) Disagree (D), strongly disagree (SD). The result of this particular item on the questionnaire is presented in Table 3.

As shown in Table 2 above, maintenance practices undertaken at the National Theatre take on different descriptions. However, most respondents $(75 \%)$ strongly agree that maintenance practices at the theatre can best be described as 'corrective maintenance to address existing problems', $25 \%$ of respondents also agree to this. Also, $50 \%$ of respondents indicated that maintenance works at the theatre may be described as 'regular check up to prevent breakdown', $30 \%$ of respondents agree and 20\% neither agree nor disagree (Tables 4 and 5).

It can also be seen from the Table 6 that $70 \%$ of respondents agree that 'breakdown maintenance after equipment failure' is common at the theatre, $12 \%$ of respondents strongly agreed to this but $12 \%$ disagreed. In addition, $68 \%$ of respondents also indicated that the theatre managers undertake 'emergency repair to quell eminent danger', $22 \%$ of respondents agreed to this but $10 \%$ disagreed.

\section{Views of Management on Maintenance Practices (Inter- view Responses)}

Two senior staff of the Estate management department of the National Theatre were interviewed for insights into the management perspectives of maintenance practices at the National Theatre. The individuals selected for the interviews were the heads of the Estate Management Department (estate managers). 
In separate interviews the estate managers presenting management perspectives indicated that several activities are undertaken to ensure the functionality of the theatre but many of these activities are routine.

\section{One estate manager explained that}

"Routine maintenance requires less technical skills, and this does not come with substantial cost, so we undertake routine maintenance very often. For example, the entire theatre is cleaned regularly; we also undertake technical servicing of air conditioners, replacement of light bulbs and painting of defaced walls".

\section{In a separate interview, another estate manager revealed that:}

"There are designated staff mandated to undertake routine maintenance. However, in every quarter general clean up exercises are organized to involve all staff in the cleaning exercise. In addition, we embark on annual maintenance during which time we try to shut down for about three weeks to do some thorough maintenance works. Last year we were supposed to shut down from somewhere in December to this year January it has been rescheduled because of the activities at the theatre"

Evidently, the goal of maintenance is mainly preservation; hence maintenance practices are often carried out to restore the operational state of an asset at a reduced cost in order to enhance the life span of the asset. In the case of the Ghana National Theatre, both the interviews and questionnaire administration reveal that several maintenance practices are undertaken or supervised by the estate department to ensure the continuous availability of the facility. Although majority of these maintenance practices are routine and mundane, there are also periodic schedules that require that the facility is closed down to the public in order to ensure that the maintenance activities are undertaken more thoroughly.

\begin{tabular}{|c|c|c|c|c|c|}
\hline Short term outcomes & SA & A & NA/DA & D & SD \\
\hline Improved work flow for occupants & $62 \%$ & $38 \%$ & 0 & 0 & 0 \\
\hline $\begin{array}{c}\text { Maintains attraction and aesthetics of } \\
\text { the building }\end{array}$ & $70 \%$ & $8 \%$ & $12 \%$ & $10 \%$ & 0 \\
\hline $\begin{array}{c}\text { Ensures the facility meets functional } \\
\text { requirements and quality standards }\end{array}$ & $100 \%$ & 0 & 0 & 0 & 0 \\
\hline $\begin{array}{c}\text { Makes building conducive for } \\
\text { occupants }\end{array}$ & $50 \%$ & $50 \%$ & 0 & 0 & 0 \\
\hline Source: Field
\end{tabular}

Source: Field Data, (2017)

Table 4: Short term outcomes of maintenance practices

\begin{tabular}{|c|c|c|c|c|c|}
\hline Medium term outcomes & SA & A & NA/DA & D & SD \\
\hline $\begin{array}{c}\text { Prevent/reduce the total closure of } \\
\text { the theatre }\end{array}$ & $78 \%$ & $2 \%$ & 0 & $20 \%$ & 0 \\
\hline $\begin{array}{c}\text { Improved coordination and efficiency } \\
\text { of scheduled maintenance }\end{array}$ & $15 \%$ & $60 \%$ & $10 \%$ & $15 \%$ & 0 \\
\hline $\begin{array}{c}\text { Reduced repair/operational cost } \\
\text { Improved quality (quality } \\
\text { management) }\end{array}$ & $10 \%$ & $25 \%$ & $25 \%$ & $40 \%$ & 0 \\
\hline
\end{tabular}

Source: Field data, (2017)

Table 5: Medium-term outcomes of maintenance practices.

\begin{tabular}{|c|c|c|c|c|c|}
\hline Maintenance practice & SA & A & NA/DA & D & SD \\
\hline $\begin{array}{c}\text { Prevent building collapse } \\
\begin{array}{c}\text { Prevent sudden breakdown of } \\
\text { building component and equipment }\end{array}\end{array}$ & $100 \%$ & $0 \%$ & 0 & 0 & 0 \\
\hline $\begin{array}{c}\text { Ensure continuous availability of the } \\
\text { theatre }\end{array}$ & $90 \%$ & $15 \%$ & 0 & 0 & 0 \\
\hline Guarantee building quality overtime & $75 \%$ & $10 \%$ & 0 & $15 \%$ & 0 \\
\hline
\end{tabular}

Source: Field data, (2007).

Table 6: Long-term benefits of maintenance practices.
The nature of maintenance practices undertaken at the National Theatre can be described as preventive and predictive. Telang opines that Preventive maintenance is very important because with building services, minimal neglect can cause potential dangers. Preventive maintenance practices include thorough cleaning, parts replacement, tightening and structural adjustment. Preventive maintenance is planned and may include activities which are started after the infrastructure has been used for a period of time. Preventive maintenance depends on the estimated probability that the infrastructure will break down or collapse when it is not maintained at a specified interval (Telang).

Related to preventive maintenance is predictive maintenance. This is also referred as condition based maintenance. In predictive maintenance, facilities are considered to deserve service attention only when direct evidence exists that deterioration has happened. This kind of maintenance is based on the need to perform maintenance only when the repair is really necessary, not after a specified period of time [12].

The manner of maintenance practices at the National Theatre as revealed in this study is in agreement with the surmise of Mohamed [5] that maintenance and quality management should not be decoupled but integrated as part of the corporate strategy to ensure continuous availability of equipment, production quality and competitive delivery. The maintenance practices of the National Theatre can also be described as depictive of quality management but not quiet. Kaufmann and Wiltschko [7] noted that quality management is procedural and structured. The International Standardization Organization ISO 9000-series defines it as coordinated activities to direct and control an organization with regard to quality. Direction and control with regard to quality generally include establishment of the quality policy and quality objectives, quality planning, quality control, quality assurance and quality improvement. Of the five indicators, maintenance practices at the theatre fall short of two: quality policy and quality improvement. This leads much to be desired because quality management is a continuum and sidestepping some of the elements would make total quality management difficult to achieve.

\section{Outcomes of the Current Maintenance Practices in the Short, Medium to Long Term?}

The second research question sought to ascertain the short term, medium term and long-term outcomes of the current maintenance practices of the National Theatre of Ghana. This research question was addressed through questionnaires and interviews.

\section{Short-term outcomes of maintenance practices}

The sampled occupants of the National Theatre of Ghana were required to indicate the extent of their agreement or otherwise about selected statements pertaining to maintenance work at the National Theatre. Responses were measured on a 5-point likert type scale which was calibrated as follow: strongly agree (SA), Agree (A), and Neither Agree nor disagree (NA/DA) Disagree (D), strongly disagree (SD). The result of this line item on the questionnaire is presented in Table 7 below.

Table 4 shows that respondents had varied opinions about the short-term outcomesof maintenance practices at the National Theatre. In spite of this, all $(\mathrm{N}=50)$ respondents strongly agree that in the short term the maintenance practices ensure that the facility meets functional requirements and quality standards. In addition, there was considerable consensus that maintenance practices help to maintain the attraction and aesthetics of the National Theatre, most respondent (70\%) strongly agreed to this, $8 \%$ agreed but $12 \%$ neither agreed nor disagreed. 
Another observable short-term outcome of maintenance practices that was given significant approval was that maintenance practices ensured improved work flow for building occupants. Majority $(62 \%)$ of respondents strongly agreed that maintenance practices improve work flow for building occupants in the short term. The remaining $38 \%$ of respondents also agreed to this statement. Further, half of respondents (50\%) strongly agreed that maintenance works make building conducive for occupants in the short term and another $50 \%$ of respondents also agreed.

\section{Medium-term outcomes of maintenance practices}

Several benefits may also accrue to maintenance practices in the medium term.

It would be observed from Table 5 that respondents varied in their responses about the outcomes of maintenance practices in the medium term. As depicted in the Table, majority (78\%) of respondents strongly agreed that maintenance practices prevent or reduce the likelihood of total closedown of the theatre, $2 \%$ of respondents also agreed but $20 \%$ disagreed. It was also found out that maintenance practices contribute to improved coordination and efficiency of scheduled maintenance in the medium term. As shown in Table $8,60 \%$ of respondents agreed that maintenance practices contribute to improved coordination and efficiency of scheduled maintenance in the medium term, $15 \%$ agreed strongly, $10 \%$ neither agreed nor disagreed but $15 \%$ disagreed. Also, most respondents (64\%) agreed that maintenance practices lead to improved quality management in the medium term. There were $10 \%$ of respondents who strongly agreed to this, $20 \%$ neither agreed nor disagreed but $6 \%$ disagreed.

\section{Long Term Benefits of Maintenance Practices}

In the long term, maintenance practices will bring about many benefits to the maintained facility. Again, respondents were required

\begin{tabular}{|c|c|c|c|c|c|}
\hline General perspectives & SA & A & NA/DA & D & SD \\
\hline $\begin{array}{c}\text { You are satisfied with the current } \\
\text { level of maintenance }\end{array}$ & $15 \%$ & $20 \%$ & $5 \%$ & $50 \%$ & $10 \%$ \\
\hline $\begin{array}{c}\text { The National Theatre has a backlog } \\
\text { of maintenance }\end{array}$ & $80 \%$ & $10 \%$ & $10 \%$ & 0 & 0 \\
\hline $\begin{array}{c}\text { There is a link between } \\
\text { maintenance and quality } \\
\text { management }\end{array}$ & $100 \%$ & 0 & 0 & 0 & 0 \\
\hline $\begin{array}{c}\text { Maintenance programs are clearly } \\
\text { expressed and communicated to } \\
\text { relevant unit and departments }\end{array}$ & $65 \%$ & $15 \%$ & $20 \%$ & 0 & 0 \\
\hline \begin{tabular}{c} 
Source: Field data (2017) \\
\hline
\end{tabular} & & & & \\
\hline
\end{tabular}

Source: Field data (2017)

Table 7: General perspectives about maintenance practices

\begin{tabular}{|c|c|c|c|c|c|}
\hline $\begin{array}{c}\text { Perspectives about current state of } \\
\text { maintenance }\end{array}$ & SA & A & NA/DA & D & SD \\
\hline $\begin{array}{c}\text { Management is not committed to } \\
\text { maintenance practices }\end{array}$ & $25 \%$ & $30 \%$ & $30 \%$ & $15 \%$ & 0 \\
\hline $\begin{array}{c}\text { Maintenance department is not well } \\
\text { equipped }\end{array}$ & $80 \%$ & $10 \%$ & $10 \%$ & 0 & 0 \\
\hline Insufficient time for implementation & $90 \%$ & $10 \%$ & 0 & 0 & 0 \\
\hline $\begin{array}{c}\text { No developed indexes for quality } \\
\text { management }\end{array}$ & $8 \%$ & $12 \%$ & $70 \%$ & $10 \%$ & 0 \\
\hline $\begin{array}{c}\text { Lack of employee commitment to } \\
\text { maintenance }\end{array}$ & 0 & 0 & 0 & $80 \%$ & $10 \%$ \\
\hline $\begin{array}{c}\text { Inadequate technical knowledge to } \\
\text { ensure efficient maintenance }\end{array}$ & $4 \%$ & $20 \%$ & $60 \%$ & $6 \%$ & $10 \%$ \\
\hline Limited budget for maintenance & $60 \%$ & $10 \%$ & $20 \%$ & 0 & 0 \\
\hline
\end{tabular}

Source: Field data (2017)

Table 8: Perspectives about the current state of maintenance. to indicate the extent of their agreement or otherwise about several statements that depict the long-term benefits of maintenance practices, and the results are presented in Table 6.

It would be observed from Table 6 that there was a wide consensus that maintenance practices prevent building collapse. As can be seen from the Table, all respondents $(\mathrm{N}=50)$ strongly agreed that maintenance practices prevent facility collapse. Also, $85 \%$ of respondents strongly agreed that maintenance practices prevent sudden breakdown of building components and equipment, the remaining $15 \%$ of respondents also agreed. In addition, majority of respondents (90\%) strongly agreed that maintenance practices ensure the continuous availability of the theatre, and $10 \%$ of respondents agreed to this. Lastly, maintenance practices also guarantee building quality overtime: $75 \%$ of respondents strongly agreed to this statement, 10\% agreed and 15\% neither agreed nor disagreed.

\section{Management views on short, medium and long-term benefits of maintenance practices}

The separate interviews from the estate managers of National Theatre revealed a lot about the benefits of the maintenance practices in the short, medium and long term. It was revealed that maintenance practices helped to ensure the comfort of the facilities' occupants and other patrons. The Estate managers explained that regular sweeping, scrubbing and repair of broken parts ensure that those who work in the facility and patrons who come for programs are comfortable during their visit.

\section{One manager explained}

Apparently, our maintenance practices make the place hygienic and conducive for work, business and pleasure. Everyone wants to be at a clean, comfortable and safe place so in the short term we do our best to meet these expectations to make the place comfortable for our patrons (verbatim response of estate manager).

It was further revealed that in the short-term maintenance practices also improve the aesthetics of the theatre. Through painting, installation of elevation lights, polishing of wood surfaces, managers of the theatre make the place more attractive and appealing to the eye.

It is undeniable that our everyday and periodic maintenance works also make the theatre more beautiful. I mean, it's a relatively old building but when you enter you'll like what you see, because we work on making the place not only available but also attractive to our patrons so that they'll continue to have their programs with us.

One estate manager commented during the interviews.

In the medium term, the maintenance practices ensure that the theatre is open for business. It was found out that maintenance practices such as constantly checking on the electrical works periodically, servicing the air conditioners and inviting experts for stage works help to ensure that the National Theatre of Ghana is fully functional as a National edifice.

One estate manager explained with an illustration;

Sometimes you hear that the theatre has been closed to the public but never entirely closed down. Anytime we do this, all we try to do is ensure that everything is working to meet standards so that when the public need to use the place, it will remain available for them. So, the continuous availability of the theatre is evidence that maintenance works have been on-going although much more needs to be done (Verbatim response of estate manager). 
The statement above captures the medium-term benefit of maintenance practices from the management perspective.

In the long term, maintenance management helps to improve the quality of the Theatre. According to managers of the facility, the National Theatre has seen several improvements in terms of building quality and these are the long-term benefits of maintenance practices. It was revealed that there have been two major maintenance works undertaken at the National Theatre since the commissioning of the facility in 1992. The first major maintenance was in 1995 when the Chinese contractors who originally constructed the theatre came to install central air condition systems and changed some of the malfunctioning electrical installations. In 2006, the second major maintenance work was also carried out and this led to the construction of disability rumps, change of glass windows, and installation of new central sound systems, electrical distribution panels and air condition.

In the view of one estate manager:

Today, the theatre is better-off than it used to be many years ago when it was built. This is because, the facility is now a modern theatre in the sense that it is disability friendly has modern stage design, improved wiring and enhanced sound and cooling system (Verbatim response of Estate manager).

The response provided above shows that the state of the Theatre has improved as a long-term benefit of maintenance works, specifically major maintenance works.

The findings of this study with regard to the second objective are acquiescent with Aartsengel and Kurtoglu [13] who sought to nest maintenance in the quality management process. According to Aartsengel and Kurtoglu [13], quality management can be ensured through continuous maintenance. This can be perceived as an organization-wide transformative initiative which is linked with generating more profits in the short-term, sustaining these gains in the long-term and making the business more competitive.

From a theoretical perspective, maintenance practices are part of quality management and hence can be modelled and measured based on certain indexes (process and results). Thus, maintenance practices are expected to be inherently beneficial on two levels; leading indicators which refer to work processes and lagging indicators which measure the outcomes of the entire maintenance process in terms of technical and economic benefit.

Leading indicators are more immediate (short to medium term) but the lagging indicators take time to manifest as these are longer term. According to Muchiri et al. [6] leading indicators such as maintenance work identification, planning, scheduling and execution are beneficial for explaining the short-term outcomes of maintenance practices whilst the lagging indicators (equipment performance and performance analysis) are suitable for explaining the medium to long term outcomes of maintenance practices.

In this regard, the maintenance practices at the National Theatre have satisfied the process indicators to the extent that maintenance is planned, scheduled and executed. However, the theatre's performance falls short of the lagging indicators to some extent because parts of the facility and some installed equipment such as the water fountain are not functioning optimally characteristic of public infrastructure $[2,14]$ also note that this is the main problem with public infrastructure in Ghana as general maintenance culture is weak.

\section{Views of senior and junior staff about the current mainte- nance practices}

The third objective of the study focused on the perspectives of respondents on maintenance practices at the National Theatre.

The perspectives were categorized into general perspectives about maintenance and the perspectives about the outcomes of maintenance practices.

The results with respect to general perspectives about maintenance management are presented in Tables.

Table 4 shows that occupants of National Theatre have different views about maintenance practices in the facility. Nevertheless, all respondents $(\mathrm{N}=50)$ agreed that there is a link between maintenance and quality management. In addition, majority $(80 \%)$ of respondents strongly agree that the National Theatre has a backlog of maintenance, $10 \%$ agreed and another $10 \%$ neither agreed nor disagreed. Further, $65 \%$ of respondents strongly agreed that maintenance programs are clearly expressed and communicated to relevant unit and departments of the organization. Meanwhile, $20 \%$ of respondents disagree to this statement and the remaining $15 \%$ agree. Again, it was evidenced that occupants were not satisfied with the level of maintenance works at the theatre as $50 \%$ of respondents disagree with the statement indicating the level of maintenance at the National Theatre is satisfactory. There are $20 \%$ of respondents who agree that the level was satisfactory, $15 \%$ strongly agree, 10 strongly disagree and 5 neither agree nor disagree.

Furthermore, the direct views of respondents about maintenance practices at the National Theatre were also gathered and the results are summarily provided in Table 8 below.

It would be observed from Table 8 that in the view of most respondents, the time available for implementing performance management practices is insufficient. Specifically, $90 \%$ of respondents strongly agreed that the time available for implementing performance management practices is limited whilst the remaining $10 \%$ of respondents agreed. Also, most respondents (80\%) strongly agreed that the maintenance department of the National Theatre is not well equipped, $10 \%$ agreed and another $10 \%$ neither agreed nor disagreed.

With respect to management commitment to maintenance practices as a major component of quality management, $30 \%$ of respondents indicated that they agree as well as neither agree nor disagree to the statement concerning management's commitment to maintenance practices at the National Theatre. However, 25\% of respondents strongly agreed that management is not committed to maintenance, $30 \%$ agreed and $15 \%$ disagreed. It appeared the greatest grey area was whether there are developed indices for the quality management of the National Theatre. Most respondents (70\%) were not sure about the existence of any such indices as they neither agreed nor disagreed to this statement, however, $12 \%$ of respondents agreed that there are no developed indices, $8 \%$ strongly agreed and $10 \%$ disagreed.

Also, respondents were unsure about whether the maintenance department had the technical knowledge to adequately maintain the theatre. Table 8 shows that $60 \%$ of respondents neither agreed nor disagreed to this statement, $20 \%$ agreed and $10 \%$ strongly agreed. Meanwhile, $60 \%$ of respondents strongly agreed that the budget for maintenance work at the National Theatre is not sufficient, $10 \%$ of respondents also agreed to this but the remaining 20\% neither agreed nor disagreed.

\section{Management perspectives about maintenance practices}

The management perspectives gave a deeper insight to maintenance practices as managers vented their concerns in more colorful detail. 
In the first place, it was revealed during both interviews that managers feel the time period for maintenance practices is not sufficient. Management perspectives presented by the estate managers of the facility showed sometimes the close down period ( 3 weeks) of the National Theatre is usually not enough to carry out the required maintenance work.

\section{One estate manager explained this as such;}

Sometimes we have to postpone scheduled maintenance because the place has been booked. We also have to quicken servicing sometimes because funds are not available when we needed it and when it eventually arrives for works to be done, there are bookings, so we have to hurry through the process (Verbatim response of Estate Manager).

Managers were also of the view that maintenance can only be executed when the materials and the funds needed for maintenance are available. Part of maintenance is to service building installations such as stand by power generators and replacement of parts of the infrastructure. These require the availability of materials or funds to purchase obsolete or damaged elements. Unfortunately, 'what flows to the kitty is not enough' as one estate manager puts it'. In the light of this, managers of the facility are constrained resource-wise.

Another estate manager puts this into perspective "we have the schedule, but if the budget is not available, we can only go as far as it can take".

This comment shows that the managers are not oblivious of the challenges of the maintenance backlog alluded to by general staff, but unfortunately there is not enough resources to support them in the execution of all the maintenance works.

In addition, management members also indicated that the public has a role to play in the maintenance of the National Theatre. Being a public place and state infrastructure, managers of the National Theatre were emphatic that members of the general public especially Ghanaian citizens have a stake in the wellbeing of the place and as such should support in the up keep of the facility. In this regard, it was revealed that the public can either directly support the maintenance of the facility through donations or simply by complying with regulations when they visit the facility.

One estate manager explained that some benevolent individuals and organizations have been supporting the work of the theatre through sponsorship.

For instance, Philips, an electronic company has provided elevation lights for the Theatre, another organization also donated woolen carpets to the National Theatre. Notwithstanding, some members of the public have make our work difficult. For example, when you say don't take food to the theatre they don't understand, some even bring in chewing gum, and this is difficult to remove when it sticks on the seats and carpet (Verbatim response of estate manager).

The perspectives about staff and management about the maintenance practices of the National Theatre confirm the conclusions of earlier studies. Particularly, Eghan observes that the dearth of maintenance culture in Ghana is worrying, but the phenomenon is even more pronounced in the public sector. Eghan suggests that the lack of a supportive maintenance culture in Ghana come at a cost as existing infrastructure and this is irritating because already there are not enough resources to maintain existing infrastructure, and nonmaintenance also comes at a cost.
These findings also support the surmise of Odediran, Opatunji and Eghenure [15] who argued that it is a common practice in the public sector to cut back on maintenance budgets especially in times of reasons scarcity. However, according to Odediran, Opatunji and Eghenure [15] this practice has been going on for some time now because the effects of poor maintenance take time to manifest in other words, the results of poor maintenance are long term as suggested by the performance measurement theoretical model posited by Munchiri et al. Also, the perspectives reported in this study confirm the conclusions of other studies such as Uma and Abidike, Cobbinah $[8,16]$, Iyagba that the state of public infrastructure leaves much to be desired.

\section{Conclusion}

The study is an assessment of public infrastructure maintenance practices in Ghana using the National Theatre of Ghana as a case in point. It is evident that there are several challenges confronting the effective and quality management of the national asset. The ensuing conclusions are drawn Based on the analysis of findings.

In the first place the predictive and preventive maintenance practices identified should be intensified by managers of the National Theatre to improve the quality of the theatre.

Also, it is essential to develop and codify a quality management policy for the National Theatre which should be made assessable to the public as a measure transparency.

Budgetary allocation for maintenance works at the National theatre also needs to be reviewed upwards to enable the maintenance department to do its work.

Finally, as the theatre did not fare very well on the lagging indicators, it is important to consider extensive major maintenance practices which also entails skills transfer to from the foreign construction company to local counterparts in Ghana, this will help ensure that the theatre remains usable and relevant as a national edifice.

Future studies may employ descriptive survey design to examine patrons' perspectives about quality of the National Theatre as public infrastructure.

\section{References}

1. Sani SI (2012) Determinant factors in development of maintenance culture in managing public asset and facilities. Int Cong Interdisc Bus Soc Sci 65: 827-832.

2. Efobi K (2014) Mass transportation system in Nigeria: Strategies for effective maintenance culture in public sector operations of Enugu State. J Energy Techn Policy 4: 14-19.

3. Khan L (2013) The potential impact of implementing project management strategies in real estate SME's of Pakistan: A case study of Sahir Associates Pvt Ltd. Unpublished thesis submitted to the Royal Docks Business School, University of East London.

4. Campbell J (1995) Up time: Strategies for excellence in maintenance management. Portland- Oregon: Productivity press.

5. Mohamed OD (2005) Identifying the barriers affecting quality in maintenance within Libyan manufacturing organizations (public sector). Salford: Unpublished dissertation submitted to Salford University school of management, Salford.

6. Muchiri P, Pintelon L, Gelders L, Martin H (2010) Development of maintenance function performance measurement framework and indicators. Int J Prod Econ 1-8.

7. Wiltschko T, Kaufmann T (2006) Quality management concept. Vienna: EUROROAD.

8. Uma KB, Abidike CP, Ihezukwu AV (2014) Maintenance culture and sustainable economic development in Nigeria: Issues, problems and prospects. Int $\mathrm{J}$ Econ Commer Manage 11: 1-11. 
Citation: Nkrumah ENK (2017) Public Infrastructure Maintenance Practices in Ghana. Review Pub Administration Manag 5: 234. doi:10.4172/23157844.1000234

9. ISO 9000 (2000) Quality management system-fundamentals and vocabulary. Geneva: International organization for standardization.

10. Kusi H (2012) Doing qualitative research- A guide for qualitative researchers. Accra: Emmpong press.

11. Creswell J (2006) Research design: Qualitative, quantitative, and mixed methods approaches. Thousand Oaks, CA: Sage.

12. Irajpour A, Najafabadi FA, Mahbod M, Mohammad K (2014) A framework to determine the effectiveness of maintenance strategies lean thinking approach. Math P Eng 14: 1-11.
13. Van Aartsengel A, Kurtoglu S (2013) A guide to continuous improvement transformation, management for professionals. Berlin: Springer, Germany.

14. Afrane SK, Osei-Tutu E (1999) Building maintenance in Ghana: Analysis of problems, practices and policy perspectives. Accra: World bank.

15. Odediran SJ, Opatunji OA, Eghenure FO (2012) Maintenance of residential buildings: Users' practices in Nigeria. J Emerg Tr in Econ Manage Sci 1-16.

16. Cobbinah PJ (2010) Maintenance of buildings of public institutions in Ghana Kumasi: Unpublished dissertation submitted to College of arts and architecture, Kwame Nkrumah University of science and technology. 